\title{
Short term fluctuations in air pollution and hospital admissions of the elderly for respiratory disease
}

\author{
Joel Schwartz
}

\begin{abstract}
Background - Several recent studies have reported associations between short term changes in air pollution and respiratory hospital admissions. This relationship was examined in two cities with substantially different levels of sulphur dioxide $\left(\mathrm{SO}_{2}\right)$ but similar levels of airborne particles in an attempt to separate the effects of the two pollutants. Significant differences in weather between the two cities allowed the evaluation of that potential confounder also.
\end{abstract}

Methods - Daily counts of admissions to all hospitals for respiratory disease (ICD 9 460-519) were constructed for persons aged 65 years and older in two cities - New Haven, Connecticut and Tacoma, Washington. Each city was analysed separately. Average daily concentrations of $\mathrm{SO}_{2}$, inhalable particles $\left(\mathbf{P M}_{10}\right)$, and ozone were computed from all monitors in each city, and daily average temperature and humidity were obtained from the US weather service. Daily respiratory admission counts were regressed on temperature, humidity, day of the week indicators, and air pollution. A 19 day weighted moving regression filter was used to remove all seasonal and subseasonal patterns from the data. Possible U-shaped dependence of admissions on temperature was dealt with using indicator variables for eight categories each of temperature and humidity. Each pollutant was first examined individually and then multiple pollutant models were fitted.

Results - All three pollutants were associated with respiratory hospital admissions of the elderly. The $\mathbf{P M}_{10}$ associations were little changed by control for either ozone or $\mathrm{SO}_{2}$. The ozone association was likewise independent of the other pollutants. The $\mathrm{SO}_{2}$ association was substantially attenuated by control for ozone in both cities, and by control for $\mathbf{P M}_{10}$ in Tacoma. The magnitude of the effect was small (relative risk 1.06 in New Haven and 1.10 in Tacoma for a $50 \mu \mathrm{g} / \mathrm{m}^{3}$ increase in $\mathbf{P} \mathbf{M}_{10}$, for example) but, given the ubiquitous exposure, this has some public health significance.

Conclusions - Air pollution concentrations within current guidelines were associated with increased respiratory hospital admissions of the elderly. The strongest evid- ence for an independent association was for $\mathbf{P M}_{10}$, followed by ozone. These results are consistent with other studies and suggest that lowering air pollution concentrations would have some impact on public health.

(Thorax 1995;50:531-538)

Keywords: air pollution, respiratory disease, hospital admissions.

The high air pollution concentrations in London in December 1952 were associated with increased mortality and hospital admissions for respiratory illness. ${ }^{1}$ Recently, analyses of data from Birmingham, $\mathrm{UK}^{2}$ and Barcelona ${ }^{34}$ have reported that black smoke and sulphur dioxide $\left(\mathrm{SO}_{2}\right)$ remained associated with increased hospital admissions for respiratory illness at the much lower air pollution concentrations that now prevail. The percentage increase in respiratory hospital admissions was also considerably lower. Similar findings have been reported from North America where ozone and airborne particles have been associated with respiratory admissions..$^{5-8}$

In all of the European studies there was a high correlation between black smoke and $\mathrm{SO}_{2}$, which makes it difficult to determine which pollutant is the primary correlate with respiratory hospital visits. Ideally, such determination would be best done by examining a location with particulate air pollution but essentially trivial levels of $\mathrm{SO}_{2}$, and vice versa. Such locations are difficult to find. However, Fairley ${ }^{9}$ did report an association between daily mortality and daily concentrations of airborne particles in Santa Clara, California, a location where $\mathrm{SO}_{2}$ concentrations are trivial. Santa Clara has no heavy industry and both industrial and domestic heating fuel are provided by natural gas. Power plants also use natural gas, so the airborne particles are primarily from motor vehicles.

No similar location with only $\mathrm{SO}_{2}$ has been reported. However, it is possible to find locations where the ratio of $\mathrm{SO}_{2}$ to airborne particles differs considerably, and comparisons of findings between such locations may therefore provide greater insight into which pollutant is the primary correlate with adverse health outcomes. Additionally, some previous studies have used linear terms for weather factors to control for their influence. However, it is possible that heat waves as well as cold weather 


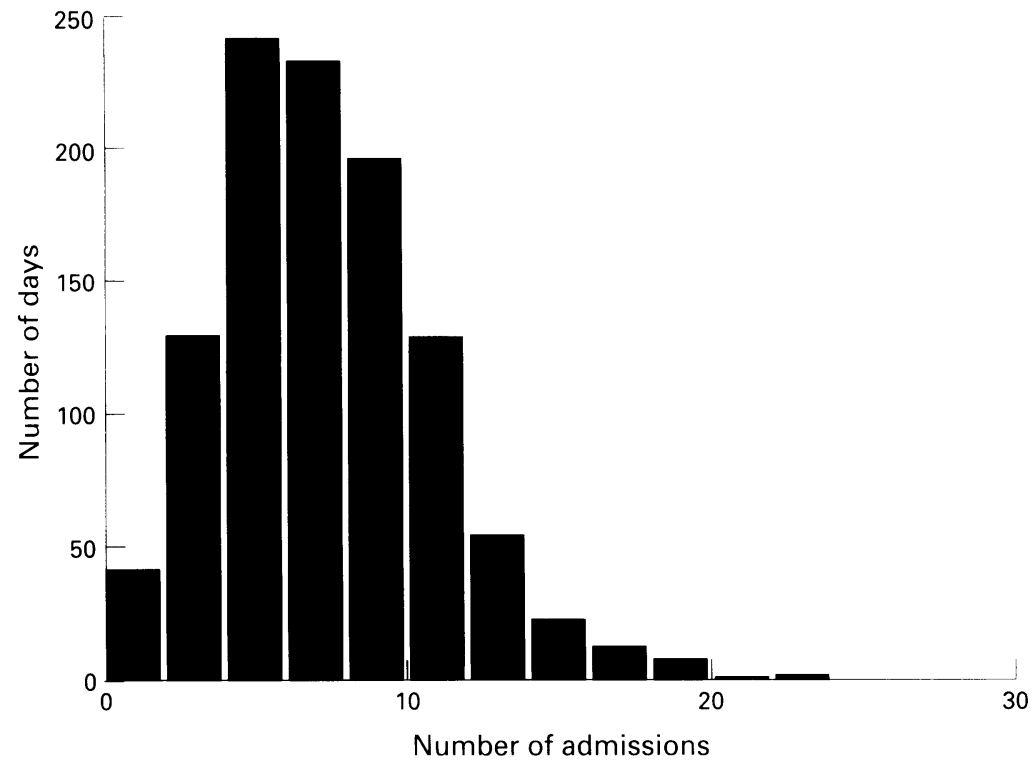

Figure 1 Histogram of the daily number of hospital admissions for respiratory causes of persons aged 65 and older in New Haven, Connecticut.

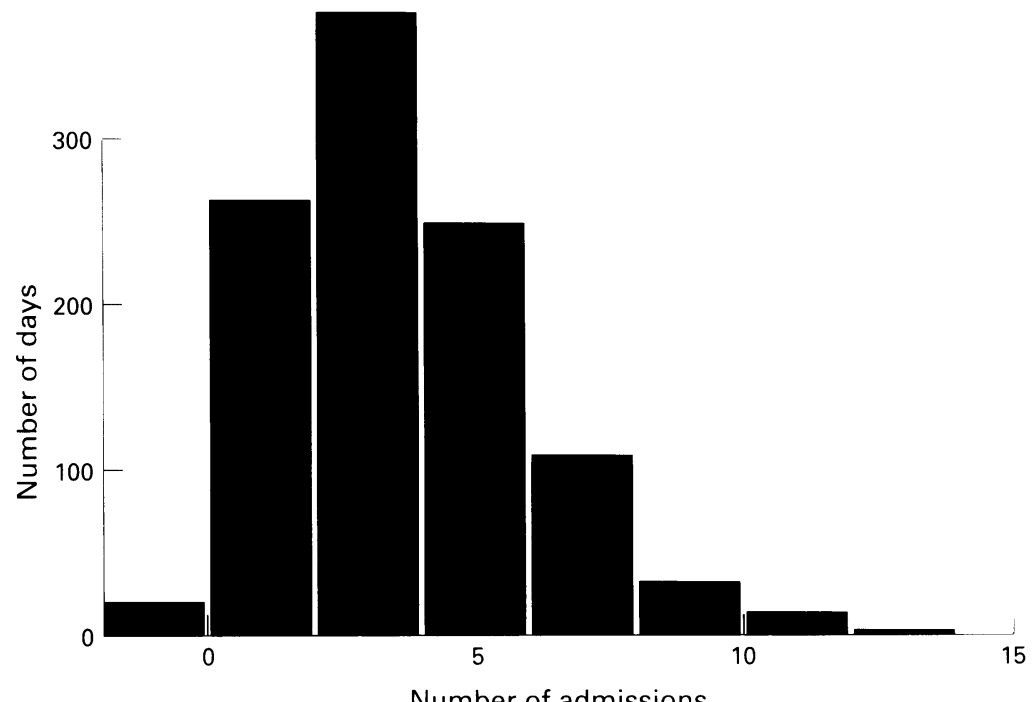

Figure 2 Histogram of the daily number of hospital admissions for respiratory causes of persons aged 65 and older in Tacoma, Washington.

are associated with increased respiratory admissions and the reported associations with pollution may still be confounded, despite the control for weather.

This study examined the association between air pollution and respiratory hospital admissions in two cities - New Haven, Connecticut and Tacoma, Washington. These cities differ in several important respects. New Haven has almost twice the mean $\mathrm{SO}_{2}$ concentration of Tacoma, almost two and a half times the $\mathrm{SO}_{2}$ concentration in the peak winter season, and a much larger summer ozone peak than Tacoma. This is partly because the weather in Tacoma is more moderate than in New Haven, with few very hot or very cold days.

\section{Methods}

HOSPITAL ADMISSIONS

The US Health Care Financing Administration $\frac{\bar{T}}{\bar{D}}$ collects standardised reports from all hospitals $\frac{\pi}{\widetilde{D}}$ for each admission of persons aged 65 and $\unrhd$ older. These reports contain the admittance के date and the International Classification for $\overrightarrow{0}$ Disease, ninth revision (ICD 9) code for the $\overrightarrow{\vec{\omega}}$ discharge diagnosis. Using these data for all $\stackrel{\omega}{\mathscr{S}}$ hospitals in the cities of New Haven, Con- $\overrightarrow{\vec{x}}$ necticut and Tacoma, Washington, daily counts if of admissions for respiratory disease (ICD 9 o 460-519) of residents were constructed for each day from 1 January 1988 to 31 December 1990.

AIR POLLUTION AND WEATHER DATA

Air pollution data were extracted from the $\vec{\varphi}$ Environmental Protection Agency's aerometric of data bank. For each day, air pollution data were extracted for all the monitoring stations in each city and averaged. In the USA airborne $\overline{0}$ particle concentrations are measured gravi- $\frac{0}{D}$

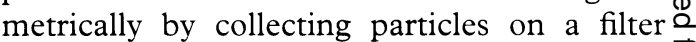
over a 24 hour period and weighing the filter. $\overrightarrow{\overrightarrow{0}}$ The particles are collected with a high volume sampler through an inlet designed only to collect particles with an aerodiameter of $10 \mu \mathrm{M}$ or less, as larger particles are not deposited in $\overrightarrow{\overline{0}}$ the respiratory tract. This particle measure-

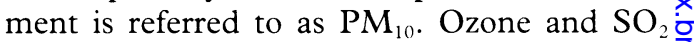
are measured hourly. For ozone and $\mathrm{SO}_{2}$ the 243 hour average of each monitor was constructed, $\stackrel{\varrho}{\circ}$ and the monitors were then averaged. For ozone, data were only available for seven윽 months of the year (April-October). Ozone $>$ monitoring was discontinued during the cold months because concentrations are very low. N Weather data were obtained from the nearest $N$ National Atmospheric and Oceanographic Ad-N ministration weather station. The 24 hour mean temperature and dew point temperature were computed from these stations.

DATA ANALYSIS

Seasonal patterns in daily counts of hospital admissions or death have long been recognised $\stackrel{\Phi}{\varrho}$ as a major potential confounder in air pollution

Table 1 Percentile points of the distribution of respiratory hospital admissions of persons aged 65 years and older and environmental variables in New Haven, 1988-90

\begin{tabular}{|c|c|c|c|c|c|c|}
\hline Variable & $10 \%$ & $25 \%$ & $50 \%$ & $75 \%$ & $90 \%$ & Mean \\
\hline Temperature $\left({ }^{\circ} \mathrm{F}\right)$ & 30 & 39 & 53 & 67 & 75 & 52 \\
\hline Dew point $\left({ }^{\circ} \mathrm{F}\right)$ & 16 & 27 & 42 & 58 & 66 & 41 \\
\hline Respiratory admissions & 4 & 5 & 8 & 10 & 13 & 8.1 \\
\hline $\mathrm{SO}_{2} \underset{\left(\mu \mathrm{ppb} / \mathrm{m}^{3}\right)}{\mathrm{pu}^{3}}$ & $\begin{array}{l}23 \\
(8 \cdot 8)\end{array}$ & $\begin{array}{c}35 \\
(13 \cdot 4)\end{array}$ & $\begin{array}{l}78 \\
(29 \cdot 8)\end{array}$ & $\begin{array}{l}100 \\
(38 \cdot 2)\end{array}$ & $\begin{array}{l}159 \\
(60 \cdot 7)\end{array}$ & $\begin{array}{l}78 \\
(29 \cdot 8)\end{array}$ \\
\hline Ozone $\left(\mu \mathrm{g} / \mathrm{m}^{3}\right)$ & $\begin{array}{l}(0.0) \\
31\end{array}$ & 41 & 53 & 69 & 89 & 56 \\
\hline (ppb) & $(15 \cdot 8)$ & $(20 \cdot 9)$ & (27) & $(35 \cdot 2)$ & $(45 \cdot 4)$ & $(28 \cdot 6)$ \\
\hline $\mathrm{PM}_{10}\left(\mu \mathrm{g} / \mathrm{m}^{3}\right)$ & 19 & 26 & 37 & 51 & 67 & 41 \\
\hline
\end{tabular}


Table 2 Respiratory hospital admissions of persons aged 65 years and older and air pollution by season in New Haven, 1988-90

\begin{tabular}{lccll}
\hline Season & Admissions & $\begin{array}{l}\mathrm{SO}_{2} \\
\left(\mu \mathrm{g} / \mathrm{m}^{3}\right)\end{array}$ & $\begin{array}{l}\text { Ozone } \\
\left(\mu \mathrm{g} / \mathrm{m}^{3}\right)\end{array}$ & $\begin{array}{l}\mathrm{PM}_{10} \\
\left(\mu \mathrm{g} / \mathrm{m}^{3}\right)\end{array}$ \\
\hline Winter & $10 \cdot 3$ & 141 & $\mathrm{NA}$ & 43 \\
Spring & $8 \cdot 4$ & 63 & 55 & 41 \\
Summer & $6 \cdot 5$ & 45 & 82 & 43 \\
Autumn & $7 \cdot 1$ & 63 & 43 & 36 \\
\hline
\end{tabular}

NA $=$ not available. data. This is illustrated in figs 1 and 2 for New Haven and Tacoma, respectively. Such data are typically treated as being Poisson rather than normally distributed. For Poisson data, subtracting the moving average can distort the distribution of the data so that it is neither normal nor Poisson, making it difficult to determine how to treat the error term in the regression. An essentially identical alternative is to put the moving average filter in the regression model itself which avoids this difficulty, ${ }^{71516}$ and this approach was used in this analysis. A 19 day averaging period was used in this analysis, as in the analysis of Burnett and coworkers. ${ }^{7}$ Further details of the filtering method used are given in the appendix. ${ }^{17}$ This approach is more stringent in removing longer wavelength patterns than seasonal dummy variables or sine waves.

Multiple regression analysis was used to regress the number of admissions for respiratory disease on the moving average filter, temperature, dew point temperature, and air pollution. The error was assumed to be Poisson distributed in the regression analysis. It seemed reasonable to suppose that if the population of the town doubled, while keeping their characteristics and all other risk factors constant, the number of increased cases due to air pollution (if any) would also double. Since the baseline number of cases would also double under that scenario, this suggests that a relative risk model is the appropriate one. This was
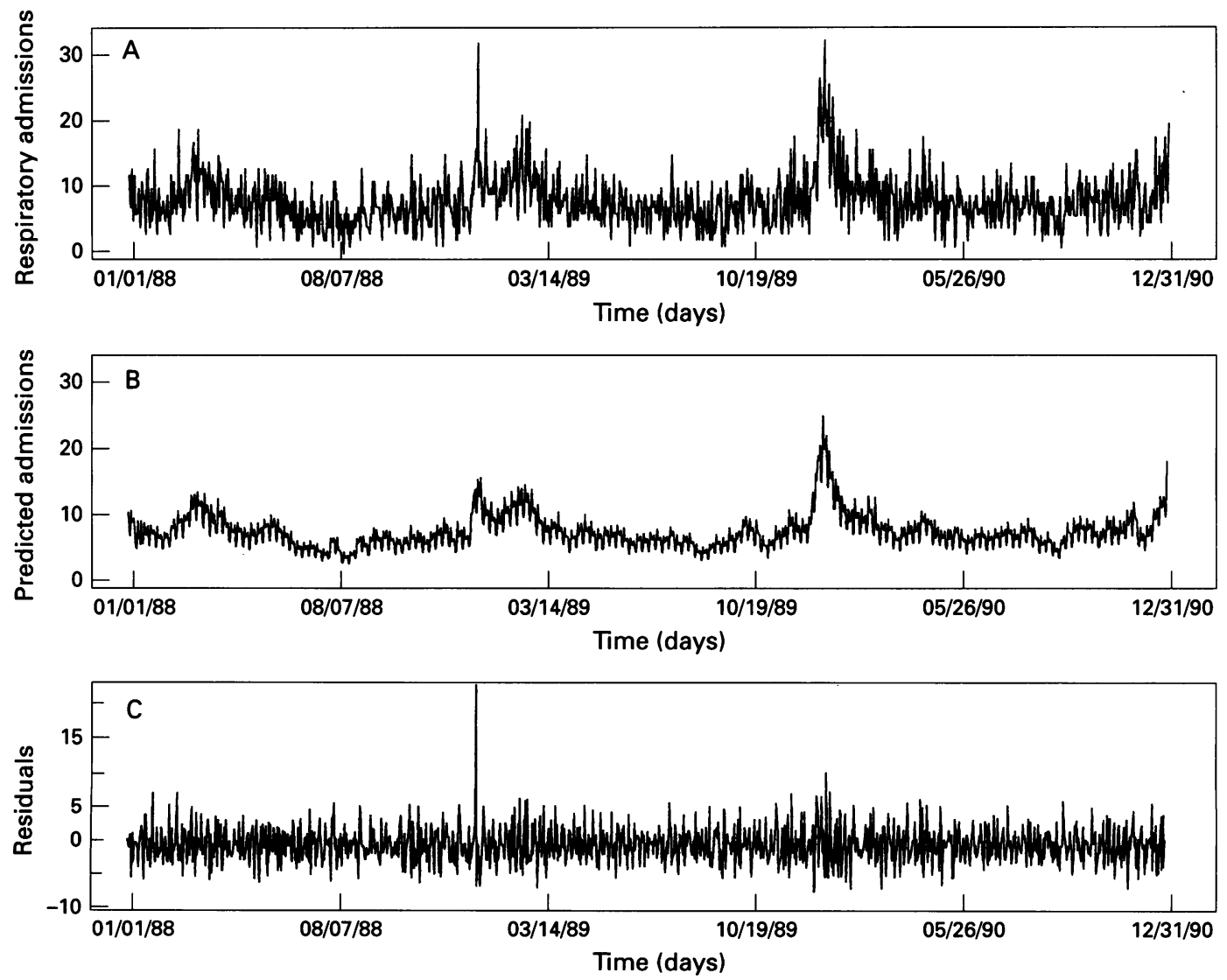

Figure 3 Plot over time of $(A)$ the daily number of hospital admissions of persons aged 65 and older in New Haven, (B) the predicted daily number of hospital admissions of persons aged 65 and older in New Haven, and (C) the residual (observed - predicted) number of daily hospital admissions of persons aged 65 and older in New Haven. The residuals are from a model which does not include air pollution. 
Table 3 Relative risk of respiratory hospital admissions and 95\% confidence intervals for a $50 \mathrm{\mu g} / \mathrm{m}^{3}$ increase in air pollution in New Haven

\begin{tabular}{llll}
\hline Pollutant & Relative risk & $95 \% \mathrm{CI}$ & $p$ \\
\hline $\mathrm{PM}_{10}$ & 1.06 & 1.13 to 1.00 & $<0.05$ \\
$\mathrm{SO}_{2}{ }^{*}$ & 1.03 & 1.05 to 1.02 & $<0.001$ \\
Ozone* & 1.06 & 1.13 to 0.99 & $>0.1$ \\
& & & \\
Two pollutant models & 1.07 & 1.14 to 1.01 & $<0.05$ \\
$\mathrm{PM}_{10}$ & 1.04 & 1.06 to 1.02 & $<0.001$ \\
$\mathrm{SO}_{2}{ }^{*}$ & 1.09 & 1.20 to 1.00 & $>0.05$ \\
$\mathrm{PM}_{10}$ & 1.07 & 1.15 to 1.00 & $>0.05$ \\
Ozone* $^{*}$ & 1.02 & 1.08 to 0.96 & 0.5 \\
SO $_{2}{ }^{*}$ & 1.05 & 1.13 to 0.98 & 0.15 \\
Ozone* $^{*}$ & & & \\
\hline
\end{tabular}

* Concentration two days before admission.

accomplished using a log linear regression. All regressions were estimated in S-Plus, ${ }^{18}$ using the generalised linear model and generalised additive model functions.

Respiratory hospital admissions may decline linearly with temperature, but it is also possible that extremely hot days increase the risk. To allow for that possibility, both temperature and humidity were divided into eight categories and indicator variables for each category were used. This allows the flexibility to fit U- or J-shaped dependencies, but does not force any nonlinearity. Indicator variables were also used for $x$ each day of the week.

Serial correlation refers to the tendency of two observations close together in time to be correlated. For example, if more persons are $\frac{\bar{D}}{\bar{D}}$ admitted today than is typical, it is likely that $\frac{\vec{\sigma}}{\overrightarrow{0}}$ more persons than average will also be admitted $\stackrel{2}{2}$ tomorrow. While most of the serial correlation कs in hospital admissions is due to seasonal pat- $\overrightarrow{0}$ terns and day of the week effects, if these terms do not fully explain that serial correlation, some $\stackrel{\omega}{\sigma}$ correlation will remain in the residuals. In this $\overrightarrow{\vec{x}}$ case the residuals are not independent of each other. Effectively, the number of independent $O r$ observations is smaller than the number of days 0

Table 4 Percentile points of the distribution of respiratory hospital admissions of persons aged 65 years and older and environmental variables in Tacoma, 1988-90

\begin{tabular}{|c|c|c|c|c|c|c|}
\hline Variable & $10 \%$ & $25 \%$ & $50 \%$ & $75 \%$ & $90 \%$ & Mean \\
\hline Temperature $\left({ }^{\circ} \mathrm{F}\right)$ & 39 & 44 & 52 & 60 & 66 & 52 \\
\hline Dew point $\left({ }^{\circ} \mathrm{F}\right)$ & 34 & 39 & 45 & 51 & 54 & 44 \\
\hline Respiratory admissions & 1 & 2 & 4 & 5 & 7 & $4 \cdot 2$ \\
\hline $\mathrm{SO}_{2} \underset{(\mathrm{ppb})}{\left(\mu \mathrm{g} / \mathrm{m}^{3}\right)}$ & 15 & 26 & 40 & 56 & $\begin{array}{c}74 \\
\end{array}$ & 44 \\
\hline Ozone $\left(\mu \mathrm{g} / \mathrm{m}^{3}\right)$ & $\begin{array}{l}(5 \cdot 7) \\
26\end{array}$ & $\begin{array}{l}(9 \cdot 9) \\
36\end{array}$ & $\begin{array}{c}(15 \cdot 3) \\
47\end{array}$ & $\begin{array}{l}(21 \cdot 4) \\
57\end{array}$ & $\begin{array}{l}(28 \cdot 2) \\
70\end{array}$ & $\begin{array}{c}(16 \cdot 8) \\
48\end{array}$ \\
\hline$(\mathrm{ppb})$ & $(13 \cdot 3)$ & $(18 \cdot 4)$ & $(24)$ & $(29 \cdot 1)$ & $(35 \cdot 7)$ & $(24 \cdot 5)$ \\
\hline $\mathrm{PM}_{10}\left(\mu \mathrm{g} / \mathrm{m}^{3}\right)$ & 14 & 20 & 30 & 47 & 67 & 37 \\
\hline
\end{tabular}
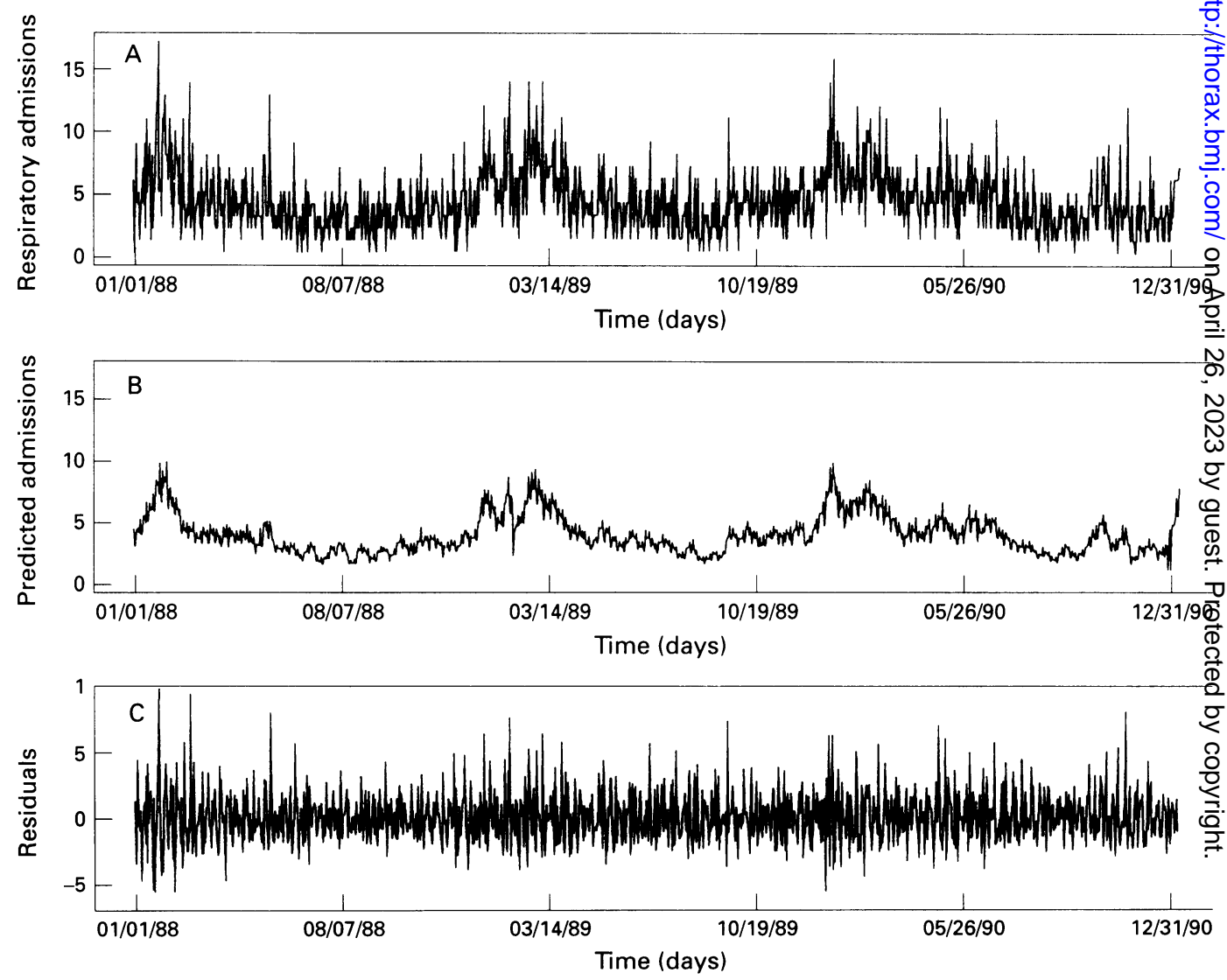

Figure 4 Plot over time of $(A)$ the daily number of hospital admissions of persons aged 65 and older in Tacoma, (B) the predicted daily number of hospital admissions of persons aged 65 and older in Tacoma, and $(C)$ the residual (observed - predicted) number of daily hospital admissions of persons aged 65 and older in Tacoma. The residuals are from a model which does not include air pollution. 
Table 5 Respiratory hospital admissions of persons aged 65 years and older and air pollution by season in Tacoma, 1988-90

\begin{tabular}{lllll}
\hline Season & Admissions & $\begin{array}{l}\mathrm{SO}_{2} \\
\left(\mu \mathrm{g} / \mathrm{m}^{3}\right)\end{array}$ & $\begin{array}{l}\text { Ozone } \\
\left(\mu g / m^{3}\right)\end{array}$ & $\begin{array}{l}\mathrm{PM}_{10} \\
\left(\mu g / m^{3}\right)\end{array}$ \\
\hline Winter & $5 \cdot 7$ & 58 & $\mathrm{NA}$ & 45 \\
Spring & $4 \cdot 6$ & 35 & 52 & 35 \\
Summer & $3 \cdot 2$ & 34 & 50 & 31 \\
Autumn & $3 \cdot 4$ & 50 & 41 & 38 \\
\hline
\end{tabular}

NA $=$ not available.

of study, and this may lead to underestimation of the standard errors of the regression coefficients. Autoregressive terms in the residuals of up to three prior days (lag 3) were examined and kept in the model when significant.

\section{Results}

Table 1 shows the distribution of the health and environmental data in New Haven. Air pollution concentrations were generally moderate. Concentrations of $\mathrm{SO}_{2}$ showed their classic behaviour, peaking in the winter with lowest concentrations occurring in the summer (table 2). There was little seasonal pattern to $\mathrm{PM}_{10}$ concentrations in New Haven. This is in contrast to most European cities, and increases the possibility that the two pollutants can be distinguished. Ozone concentrations showed the expected summer peaks.

Figure 3 shows a plot of three series versus day of study in New Haven; fig. 3A shows the original series of respiratory admissions for the elderly, fig 3B the predicted admissions using the model with control for season, temperature, and humidity, and day of the week, but not air pollution, and fig $3 \mathrm{C}$ shows the residuals (the difference between the actual and predicted). No seasonal or other long term patterns are apparent in the residuals but there is one outlier value. That day (1 January 1989) was excluded from the final analyses using air pollution to assure that any associations were not driven by one extreme value.

Table 3 shows the results of adding air pollution to the basic regression model. Pollution on the day of admission and one or two days before the admission was considered. $\mathrm{PM}_{10}$ on the same day and $\mathrm{SO}_{2}$ levels two days before were significant predictors of hospital admissions for respiratory disease. The ozone level two days before admission was a marginal

Table 6 Relative risk of respiratory hospital admissions and 95\% confidence intervals for a $50 \mu \mathrm{g} / \mathrm{m}^{3}$ increase in air pollution in Tacoma

\begin{tabular}{llll}
\hline Pollutant & Relative risk & $95 \% \mathrm{CI}$ & $p$ \\
\hline $\mathrm{PM}_{10}$ & 1.10 & 1.17 to 1.03 & $<0.005$ \\
$\mathrm{SO}_{2}$ & 1.06 & 1.12 to 1.01 & $>0.02$ \\
Ozone* & 1.21 & 1.38 to 1.06 & $<0.005$ \\
Two pollutant models & & & \\
$\mathrm{PM}_{10}$ & 1.11 & 1.20 to 1.02 & 0.01 \\
$\mathrm{SO}_{2}$ & 0.99 & 1.06 to 0.93 & $>0.5$ \\
$\mathrm{PM}_{10}$ & 1.12 & 1.29 to 0.97 & $>0.1$ \\
Ozone* $_{\text {SO }}$ & 1.20 & 1.37 to 1.06 & $<0.01$ \\
Ozone* $^{*}$ & 0.93 & 1.04 to 0.83 & 0.2 \\
\hline
\end{tabular}

* Concentration two days before admission. predictor of hospital admissions. However, the sample size for the ozone analysis was reduced by over $40 \%$. To make the results meaningful and comparable, all three pollutants are expressed in units of $50 \mu \mathrm{g} / \mathrm{m}^{3}$. This represents a moderately large pollution difference, but one that is observed in the data.

Two pollutant models were then examined to determine which pollutants made independent contributions to explaining respiratory hospital admissions. Ozone was included in these models because, while its significance was marginal in this analysis, the effect size was similar to that reported in other studies. ${ }^{67}$ The $\mathrm{PM}_{10}$ and $\mathrm{SO}_{2}$ associations appeared to be independent of each other. The $\mathbf{P M}_{10}$ and ozone associations also appeared to be independent of each other, with no reduction in the relative risk for one pollutant after control for the other. The substantial reduction in sample size did make the $\mathrm{PM}_{10}$ association only marginally significant in this analysis, however. In contrast, the $\mathrm{SO}_{2}$ association was substantially reduced in magnitude and became quite insignificant after control for ozone. The ozone association was little changed by control for $\mathrm{SO}_{2}$.

Table 4 shows the distribution of hospital admissions and environmental data in Tacoma. There were only four respiratory admissions per day in Tacoma, about half the number seen in New Haven. While the mean temperature and humidity were similar between the two locations, Tacoma had a more moderate and less variable climate than New Haven. The 90th percentile of temperature and dew point in Tacoma were 66 and 54, respectively, compared with 75 and 66 for New Haven. The low temperatures were similarly less extreme. $\mathbf{P M}_{10}$ and ozone concentrations were similar between the two cities, but $\mathrm{SO}_{2}$ levels were considerably lower in Tacoma. $\mathrm{PM}_{10}$ showed a distinct winter peak in Tacoma (table 5) and $\mathrm{SO}_{2}$ levels were almost as high in the autumn as in the winter.

Figure 4A shows the plots of hospital admissions for respiratory disease versus day of study in Tacoma, fig 4B shows the predicted series, using the model without air pollution, and fig $4 \mathrm{C}$ shows the residuals. No outliers or long wavelength patterns were present in the residuals.

Table 6 shows the regression results for air pollution. As in New Haven, $\mathrm{PM}_{10}$ on the same day and ozone two days before were associated with respiratory admissions in Tacoma. In the case of $\mathrm{SO}_{2}$, it was the value on the same day rather than two days before that was predictive of hospital admissions. In two pollutant models $\mathrm{SO}_{2}$ was no longer significant after $\mathrm{PM}_{10}$ was controlled for. $\mathrm{PM}_{10}$ remained associated with respiratory admissions after control for $\mathrm{SO}_{2}$, however, with a similar magnitude risk. Sulphur dioxide was also insignificant when ozone was controlled for. The association with $\mathrm{PM}_{10}$ became marginal with control for ozone. However, the magnitude of the $\mathrm{PM}_{10}$ effect was not reduced by control for ozone, and inclusion of ozone in the regression model eliminated five months of each year when ozone was not monitored. 
Table 7 Relative risk of respiratory hospital admissions for a $50 \mu \mathrm{g} / \mathrm{m}^{3}$ increase in air pollution from selected recent studies

\begin{tabular}{|c|c|c|c|c|}
\hline Location & Outcome & Pollutant & Relative risk & $95 \% C I$ \\
\hline $\begin{array}{l}\text { New Haven } \\
\text { Tacoma } \\
\text { Birmingham, AL } \\
\text { Birmingham, AL } \\
\text { Barcelona (winter) } \\
\text { Barcelona (summer) } \\
\text { Ontario } \\
\text { New York } \\
\text { New Haven } \\
\text { Tacoma } \\
\text { Birmingham } \\
\text { Ontario } \\
\text { New York } \\
\text { Barcelona (winter) } \\
\text { Barcelona (summer) } \\
\text { New Haven } \\
\text { Tacoma }\end{array}$ & $\begin{array}{l}\text { All respiratory } \\
\text { All respiratory } \\
\text { COPD } \\
\text { Pneumonia } \\
\text { COPD } \\
\text { COPD } \\
\text { All respiratory } \\
\text { All respiratory } \\
\text { All respiratory } \\
\text { All respiratory } \\
\text { Pneumonia } \\
\text { All respiratory } \\
\text { All respiratory } \\
\text { COPD } \\
\text { COPD } \\
\text { All respiratory } \\
\text { All respiratory }\end{array}$ & $\begin{array}{l}\mathrm{PM}_{10} \\
\mathrm{PM}_{10} \\
\mathrm{PM}_{10} \\
\mathrm{PM}_{10} \\
\mathrm{PM}_{10}{ }^{*} \\
\mathrm{PM}_{10}{ }^{*} \\
\mathrm{PM}_{10} \dagger \\
\mathrm{PM}_{10} \ddagger \\
\text { Ozone } \\
\text { Ozone } \\
\text { Ozone } \\
\text { Ozone } \\
\text { Ozone } \\
\text { SO } \\
\text { SO }_{2} \\
\text { SO }_{2} \\
\mathrm{SO}_{2}\end{array}$ & $\begin{array}{l}1.06 \\
1 \cdot 1 \\
1 \cdot 13 \\
1.09 \\
1 \cdot 11 \\
1.08 \\
1.09 \\
1.07 \\
1.06 \\
1 \cdot 21 \\
1.07 \\
1 \cdot 17 \\
1.26 \\
1.13 \\
1.19 \\
1.03 \\
1.06\end{array}$ & $\begin{array}{l}1.13 \text { to } 1.00 \\
1.17 \text { to } 1.03 \\
1.22 \text { to } 1.04 \\
1.15 \text { to } 1.03 \\
1.15 \text { to } 1.06 \\
1.19 \text { to } 0.79 \\
\text { NC } \\
\text { NC } \\
1.13 \text { to } 0.99 \\
1.37 \text { to } 1.06 \\
1.18 \text { to } 0.99 \\
\text { NC } \\
\text { NC } \\
1.21 \text { to } 1.06 \\
1.34 \text { to } 1.06 \\
1.05 \text { to } 1.02 \\
1.12 \text { to } 1.01\end{array}$ \\
\hline
\end{tabular}

* Converted from black smoke assuming a ratio of $1: 1$.

+ Converted from $\mathrm{SO}_{4}$ assuming a ratio of $2 \cdot 5: 1$ based on data from Ontario.

$\ddagger$ Converted from $\mathrm{SO}_{4}$ assuming a ratio of $4: 1$ based on data from Eastern US cities.

$\$$ Maximum ozone converted to mean ozone assuming a ratio of $2 \cdot 5: 1$.

$\mathrm{NC}=$ not computed.

\section{Discussion}

All three pollutants showed evidence of association with hospital admissions for respiratory disease in both cities in this study. The most consistent association was seen for $\mathbf{P M}_{10}$. It was significant in both cities, and control for either of the other pollutants did not reduce the estimated size of the $\mathrm{PM}_{10}$ effect. Both cities were also consistent regarding which lag of $\mathrm{PM}_{10}$ was associated with respiratory hospital admissions. Ozone was associated with respiratory hospital admissions with a two day lag in both cities, although the association was weak in New Haven. The association with ozone also appeared to be independent of the other two pollutants. For $\mathrm{SO}_{2}$, in contrast, the association was less consistent. The lag structure was different between New Haven and Tacoma, and in both cities control for ozone substantially weakened the association with $\mathrm{SO}_{2}$. In Tacoma, but not New Haven, the $\mathrm{SO}_{2}$ association also disappeared after control for $\mathrm{PM}_{10}$.

The difference in weather between the two cities provides a useful counterpoint. The 10th percentile of temperature in Tacoma was almost $10^{\circ} \mathrm{F}$ warmer than in New Haven. The lack of cold winters is partially responsible for the lower winter peak in $\mathrm{SO}_{2}$ in Tacoma. The $\mathrm{SO}_{2}$ association was less stable in Tacoma. This suggests either that a threshold exists, which was less often exceeded in Tacoma, or that the association in New Haven was confounded by weather or other pollutants. The reduction in the size and significance of the $\mathrm{SO}_{2}$ effect in New Haven after control for ozone could also reflect a threshold for the $\mathrm{SO}_{2}$ effect, since ozone was not monitored in the winter when $\mathrm{SO}_{2}$ was highest. However, the levels of $\mathrm{SO}_{2}$ in the other seasons in New Haven were similar to those seen in Tacoma in all seasons, suggesting that this is not just a seasonal or threshold phenomenon. The persistence of the $\mathbf{P M}_{10}$ association in the city with the milder winters suggests that the association is not confounded by cold weather.

Tacoma also had milder weather in the summer, with fewer hot hazy days than New Haven. As a result, summer ozone concentrations in
Tacoma were only about $60 \%$ of those in New $\stackrel{\mathrm{\omega}}{\rightarrow}$ Haven. Despite this, the association with ozone 9 in Tacoma was stable and the estimated effect $\vec{r}$ was larger. One possible explanation for these results is that hot and humid weather is associated with increased use of air conditioning $\ddot{\theta}$ and decreased time outdoors, both of which would reduce actual exposure at a given out- $\triangle$ door concentration. In fact, the magnitude of the effect of all three pollutants was larger in the city with the milder weather, although the $\frac{0}{\infty}$ confidence intervals overlap, suggesting that $\propto$ pollution effects are easier to see in the absence $\overrightarrow{\vec{B}}$ of extreme weather conditions. This has important implications for study design and risk assessment, and further investigation is needed to confirm this finding.

The association with $\mathrm{PM}_{10}$ in Tacoma was not weakened by the coincident $\mathrm{SO}_{2}$ con- $-\dot{0}$ centrations being lower. This suggests that the 3 $\mathrm{PM}_{10}$ association is not due to confoundingo with $\mathrm{SO}_{2}$. Indeed, the $\mathrm{PM}_{10}$ association in both? cities remained significant after control for $\mathrm{SO}_{2}$. $\frac{}{3}$ This differs from the experience in most Euro- $\rightarrow$ pean cities. However, in those studies blackㅡㅡㄹ smoke (the particle measure used) was highlyN correlated with $\mathrm{SO}_{2}$.

Airborne particles have been associated with reduced pulmonary function, ${ }^{19-21}$ increased ${ }_{O}$ respiratory symptoms, ${ }^{192022-25}$ increased respiratory illness ${ }^{2627}$ or school absence, ${ }^{28}$ in creased chronic respiratory symptoms ${ }^{29-31}$ or chronic reduction in pulmonary function, ${ }^{3233} \mathrm{O}$ increased hospital admissions or emergency room visits, ${ }^{3-834}$ and increased mortality, par- ticularly from respiratory disease. ${ }^{935-38}$ These $\stackrel{\circ}{2}$ studies have been conducted in cities with widely varying climates and coincident weathero conditions. They have included studies witho essentially no coexposure to $\mathrm{SO}_{2}{ }^{919202837}$ and studies with essentially no coexposure to $\rightleftharpoons$ ozone. ${ }^{9-1119-212538}$ The combined weight of these studies suggests that the association between airborne particles and adverse respiratory outcomes is unlikely to be due to confounding.

The epidemiological evidence that ozone is a risk factor in respiratory illness is weaker, but still substantial. Ozone has been associated with an increase in the risk of respiratory 
symptoms, ${ }^{232439}$ reductions in pulmonary function in both experimental and epidemiological studies, ${ }^{40-44}$ and hospital admissions or emergency room visits. ${ }^{5-8}$ Taken together, the weight of the evidence supports the conclusion that ozone concentrations below current standards are associated with exacerbation of illness.

The situation with $\mathrm{SO}_{2}$ is more mixed. Studies in Europe consistently report associations with $\mathrm{SO}_{2},{ }^{2-4}$ but the correlation between $\mathrm{SO}_{2}$ and airborne particles is high in all of these studies. In studies where the correlation between $\mathrm{SO}_{2}$ and airborne particles was lower, weaker or no associations were seen with $\mathrm{SO}_{2}{ }^{539}$ In locations with low concentrations of $\mathrm{SO}_{2}$ the associations seen with airborne particles were similar to those seen in Europe. ${ }^{1920}$ All this suggests that the observed $\mathrm{SO}_{2}$ associations are confounded by airborne particles. Further examination of locations with low correlations between the two pollutants, or with very low concentrations of one pollutant, will be needed to confirm or refute this conclusion.

No epidemiological study can preclude the possibility of confounding. This makes comparisons with results in other studies important since the association between air pollution and any omitted confounders will probably vary by location. Table 7 shows estimated relative risks for $50 \mu \mathrm{g} / \mathrm{m}^{3}$ increments in each pollutant from selected recent studies. It should be noted that the same measure of airborne particle concentration was not available in each location, and the conversions that have been made are only rough approximations. The consistency of effect size estimates is moderate, with the $\mathrm{PM}_{10}$ associations being the most stable. Further studies, particularly in areas which have predominantly one pollutant, will be important in clarifying the relative role of individual pollutants. It seems clear, however, that air pollution is associated with respiratory morbidity at concentrations commonly occurring in western countries. It should be noted that a $50 \mu \mathrm{g} /$ $\mathrm{m}^{3}$ increase in air pollution is quite large in western countries, and that the associated relative risk is small. However, since exposure to some level of air pollution is ubiquitous, the attributable risk is not negligible. In New Haven and Tacoma air pollution appears to be responsible for perhaps $5 \%$ of the respiratory hospital admissions of the elderly. There is no possibility of reducing air pollution levels to zero, but it might be possible to reduce them by $20 \%$. If so, a $1 \%$ reduction in hospital admissions might be expected in these locations. While not large, such a reduction is also not trivial.

\section{Appendix}

The use of a 15 day moving average to approximate the longer term pattern in the mortality data was an example of a non-parametric smooth curve. It is called non-parametric because the moving average generates a curve of expected mortality versus day of the year without specifying a particular functional form for the curve, or estimating the parameters of that function. The field of non-parametric smoothing is now quite extensive, and good introductions to it exist. ${ }^{13-15}$ In general it is desirable to use weighted moving averages, with weights that decline with distance from the centre of the moving average period. This approach makes heuristic sense - points farther from the day being predicted presumably should be given less weight in predicting the expected number of deaths on that day. It also has a more technical justification. A sharp cutoff in the weight given to points (such as a weight of 1 for seven days ago and of 0 for eight days ago in the 15 day moving average) creates distortions in the amplitude and phase of the short term patterns of fluctuations remaining after subtracting the moving average of mortality. These are the patterns we wish to correlate with air pollution. Weights also reduce variance in the estimated number of daily deaths. A modification of the moving average approach is the moving regression approach. ${ }^{17}$ In loess, ${ }^{17}$ a weighted moving regression is used because moving regressions are better behaved at the boundaries of the data.

For Gaussian data the residuals of mortality, after subtracting the moving average or moving regression, can be regressed against the residuals of weather and pollution terms, after subtracting their moving averages or moving regressions. For Poisson data this cannot be done, since the filtered data no longer have a Poisson distribution. However, the same results can effectively be obtained by putting the filter in the regression model. This can be accomplished in a number of ways, but the most elegant is using the generalised additive model. ${ }^{15}$ This specifies, in our case, that the natural logarithm of the expected number of daily deaths can be written as a sum of the weather, day of week, and pollution terms plus a moving average or moving regression over time. In fact, smooth functions of weather and air pollution can also be specified, although in this analysis that was not done. The details of the generalised additive model have been extensively discussed. ${ }^{15}$

1 Mortality and morbidity during the London fog of December 1952. Report No 95, Public Health and Medical Subjects. London: HMSO, 1954.

2 Walters S, Griffiths RK, Ayres JG. Temporal association between hospital admissions for asthma in Birmingham and ambient levels of sulphur dioxide and smoke. Thorax 1994;49:133-40.

3 Sunyer J, Anto JM, Murillo C, Saez M. Effects of urban air pollution on emergency room admissions for chronic obstructive pulmonary disease. Am $\mathcal{F}$ Epidemiol 1991;134 277-86.

4 Sunyer J, Saez M, Murillo C, Castelsaque J, Martinez F, Anto JM. Air pollution and emergency room admissions for chronic obstructive pulmonary disease: a 5-year study. Am $₹$ Epidemiol 1993;137:701-5.

5 Bates DV, Szito R. Hospital admissions and air pollutants in Southern Ontario: the acid summer haze effect. Environ Res 1987;43:317-31.

6 Thurston GD, Ito K, Kinney PL, Lippman M. A multiyear study of air pollution and respiratory hospital admissions in three New York State metropolitan areas: results for 1988 and 1989 summers. 7 Expos Anal Environ Epidemio 1992;2:429-50.

7 Burnett RT, Dales RE, Raizenne ME, Krewski D, Summers PW, Roberts GR, et al. Effects of low ambient levels of ozone and sulfates on the frequency of respiratory of ozone and sulfates on the frequency of respiratory 172-94.

8 Schwartz J. Air pollution and hospital admissions for the elderly in Birmingham, AL. Am $f$ Epidemiol 1994;139: 589-90.

9 Fairley D. The relationship of daily mortality to suspended 
particulates in Santa Clara County, 1980-1986. Environ Health Perspect 1990;89:159-68.

10 Mazumdar S, Schimmel H, Higgins ITT. Relation of daily mortality to air pollution: an analysis of 14 London winters 1958/59-1971/72. Arch Environ Health 1982;37:213-20.

11 Schwartz J, Marcus A. Mortality and air pollution in London: a time series analysis. Am $\mathcal{F}$ Epidemiol 1990;131: 185-94.

12 Ostro BD. A search for a threshold in the relationship of air pollution to mortality: a reanalysis of data on London winters. Environ Health Perspect 1984;68:397-9.

13 Härdle W. Smoothing techniques with implementation in $S$. New York: Springer-Verlag, 1991.

14 Chambers JM, Cleveland WS, Kleiner B, Tukey PA. Graphical methods for data analysis. Pacific Grove, CA: Wadsworth Press, 1983

15 Hastie T, Tibshirani R. Generalized additive models. London: Chapman and Hall, 1990.

16 Schwartz J, Spix C, Wichmann HE, Malin E. Air pollution and acute respiratory illness in five German communities. Environ Res 1991;56:1-14.

17 Cleveland WS, Devlin SJ. Robust locally-weighted regression and smoothing scatterplots. F Am Stat Assoc 1998 47:829-36.

18 Statistical Sciences Inc. S-PLUS for Windows User Manual. Seattle: Statistical Sciences Inc, 1993

19 Pope CA, Dockery DW, Spengler JD, Raizenne ME. Respiratory health and $\mathbf{P M}_{10}$ pollution: a daily time series spiratory health and $\mathrm{PM}_{10}$ pollution: a daily

20 Pope CA III, Dockery DW. Acute health effects of PM $_{1}$ pollution on symptomatic and asymptomatic children. $A m$ Rev Respir Dis 1992;145:1123-8.

21 Dasen W, Brunekreef B, Hoek G, et al. Decline in children's pulmonary function during an air pollution episode. Fournal of the Air Pollution Control Association 1986;36:1233.

22 Braun-Fahrlander C, Ackermann-Liebrich U, Schwartz J, Gnehm HP, Rutishauser M, Wanner HU. Air pollution and respiratory symptoms in preschool children. Am Rev and respiratory symptoms

23 Krupnick AJ, Harrington W, Ostro BD. Ambient ozone and acute health effects: evidence from daily data. $\mathcal{f}$ Environ Econ Manag 1990;18:1-18.

24 Ostro BD, Rothschild S. Air pollution and acute respiratory morbidity: an observational study of multiple pollutants. Environ Res 1989;50:238-47.

25 Hoek G, Brunekreef B. Acute effects of a winter air pollution episode on pulmonary function and respiratory symptoms episode on pulmonary function and respiratory sym

26 Dockery DW, Speizer FE, Stram DO, Ware JH, Spengler JD, Ferris BG Jr. Effects of inhaled particles on respiratory health of children. Am Rev Respir Dis 1989;39:587-94

27 Schwartz J, Spix C, Wichmann HE, Malin E. Air pollution and acute respiratory illness in five German communities. Environ Res 1991;56:1-14.

28 Ransom MR, Pope CA III. Elementary school absences and $\mathrm{PM}_{10}$ pollution in Utah Valley. Environ Res 1992;58: 204-19.
29 Abbey DE, Petersen F, Mills PK, Beeson WL. Long term ambient concentrations of total suspended particulates, ozone, and sulfur dioxide and respiratory symptoms in a non-smoking population. Arch Environ Health 1993;48: 33-46.

30 Vedal S, Blair J, Manna B. Adverse respiratory health effects of ambient inhalable particle exposure. Air and Waste Management Association, Vancouver, 1991, Paper 91- $\overrightarrow{ }$ 180.56 .

31 Schwartz J. Particulate air pollution and chronic respiratory symptoms. Environ Res 1993:62:7-14.

32 Chestmut LG, Schwartz J, Savitz DA Burchfiel CM. Pul- = monary function and ambient particulate matter: epi- $\overline{9}$ demiological evidence from NHANES I. Arch Environ Health 1991;46:135-44.

33 Schwartz J. Lung function and chronic exposure to air $\underline{\sigma}$ pollution: a cross-sectional analysis of NHANES II. Envimn Res 1989;50:309-21.

34 Schwartz J, Koenig J, Slater D, Larson T. Particulate air $\mathrm{Q}$ pollution and hospital emergency visits for asthma in Peattle. Am Rev Respir Dis 1993;147:826-31.

35 Schwartz J, Dockery DW. Particulate air pollution and daily $\vec{\circ}$ mortality in Steubenville, Ohio. Am $\mathcal{F}$ Epidemiol 1992;135: 12-20.

36 Schwartz J, Dockery DW. Increased mortality in Phil- $\vec{\omega}$ adelphia associated with daily air pollution concentrations. Am Rev Respir Dis 1992;145:600-4.

37 Pope $\mathrm{CA}$ Schwartz J, Ransom $M$. Daily mortality and $P M_{10} \times$ pollution in Utah Valley. Arch Environ Health 1992;42: G pollution

38 Spix C, Heinrich J, Dockery D, Schwartz J, Völksh G, U Schwinkowski $\mathrm{K}$, et al. Air pollution and daily mortality $\omega^{-}$ in Erfurt, East Germany from 1980 to 1989. Envirn Health Perspect 1993;101:518-26.

39 Schwartz J. Air pollution and the duration of acute respiratory symptoms. Arch Environ Health 1992;42:116-22.

40 Brunekreef B, Kinney PL, Ware JH, Dockery DW, Speizer $\mathrm{FE}$, Spengler JD, et al. Sensitive subgroups and normal $\mathrm{FE}$, Spengler JD, et al. Sensitive subgroups and normal variation in pulmonary function in response to air po

41 Castillejos M, Gold DR, Dockery DW, Tosteson T, Baum eै $T$, Speizer FE. Effects of ambient ozone on respiratory function and symptoms in Mexico City schoolchildren. Am Rev Respir Dis 1992;145:275-82.

42 Horstman DH, Folinsbee LJ, Ives PJ, Abdul-Salaam S, McDonnell WF. Ozone concentrations and pulmonary function response relationships for 6.6 hour exposures with five hours of moderate exercise to $0.08,0.10$, and 0.12 ppm. Am Rev Respir Dis 1989;138:407-15.

43 Kinney P, Ware JH, Spengler JD, Dockery DW, Speizer FE, Ferris BG Jr. Short term pulmonary function change in $\mathrm{O}$ association with ozone levels. Am Rev Respir Dis 1989; 139:56-61.

44 Hoek G, Brunekreef B, Kosterink P, Berg RVD, Hofschreuder P. Effect of ambient ozone on peak expiratory flow of exercising children in the Netherlands. Arch Environ Health 1993;48:27-32. 